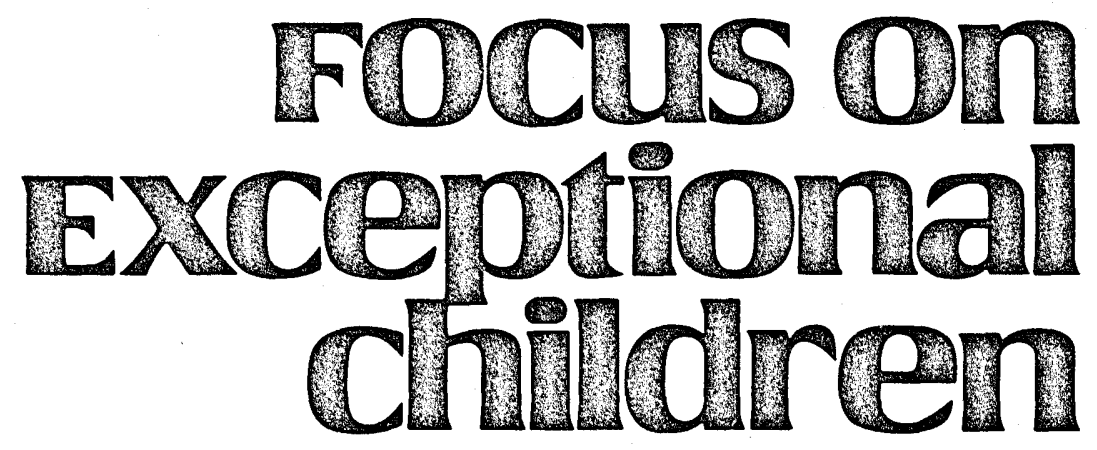

\title{
Developing Curriculum-Based Measurement Systems For Data-Based Special Education Problem Solving
}

\section{Stanley L. Deno and Lynn S. Fuchs}

Special education is characterized most often as a service delivery system (Deno, 1970). Indeed, The Education for All Handicapped Children Act (Public Law 94-142) is written to guarantee provision of educational services to all students classified as handicapped. Although viewing special education as a service delivery system may be useful, this conceptualization tends to cast special education in the mold of a welfare program, designed to serve an educationally needy segment of the population through special funding. An alternative-perhaps more constructive-conceptualization is to view special education as a component of the general education system, designed to solve individual students' problems.

The advantage of recasting special education as a problem-solving mechanism is that programmatic goals can be specified more precisely, and the steps or procedures for solving the problems for which special education was created can be identified more clearly. Consider the generic steps folowed in problem-solving activities:

1. Identify the problem to be solved.

2. Identify alternative solutions to the problem.

3. Implement and test the alternative solutions.

4. Revise unsuccessful solutions.

5. Terminate the problem-solving process.

How do we apply these steps to describe special education practice? The answer to this question is apparent when we recast the problem-solving steps as the following series of decisions special educators formulate in building effective educational programs:

1. What are the problems that gave impetus to referral to special education and suggest the need for modifying the student's program?

2. What alternative individual education plans can be created that might solve these problems?

3. Have we implemented the Individualized Education Program (IEP) designed to solve problems that led to referral, and does the problem solution appear to be effective?

4. Have we revised an unsuccessful attempt at problem solution, and does that revised problem solution appear to be more successful?

5. Does evidence exist that the problems that led to referral have been solved and the student may be exited from special education?

Dr. Deno is a Professor in the Department of Educational Psychology, Special Education Programs, University of Minnesota. Dr. Fuchs is Assistant Professor, Department of Special Education, Peabody College of Vanderbilt University.

- Love Publishing Company, 1987. 
When special education is viewed in terms of these questions, which correspond to the generic problem-solving process, the essence of special education becomes constructive problem solving, whatever the overlay of regulations and policies created through federal and state laws. The focus of special education shifts from simply serving handicapped students through special resources to solving pupils' problems in order to produce optimal progress in least restrictive environments.

Problem solving in this regard can be approached as an entirely intuitive and subjective process, but it also is possible to approach problem solving systematically and objectively. Although intuitive approaches to problem solving may be valuable, in special education we increasingly have been required to objectify the basis for our decisions. The process that produces the greatest objectification in human endeavor is, of course, measurement. Now, more than ever, we are required to provide data not only to justify the allocation of resources but also to demonstrate the effectiveness of problem-solving efforts we undertake.

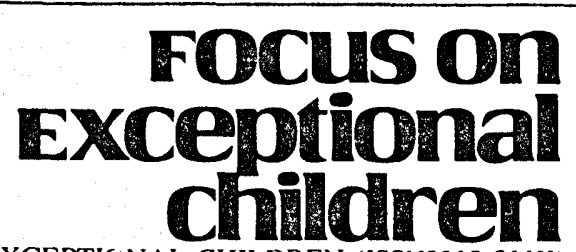

FOCUS ON EXCEPTIONAL CHILDREN (ISSN0015-511X) (USPS 203-360) is published monthly except June, July, and August as a service to teachers, special educators, curriculum specialists, administrators, and those concerned with the special education of exceptional children. This journal is abstracted and indexed in Exceptional Child Education Resources, and is also available in microform from Xerox University Microfilm, Ann Arbor, Michigan. Subscription rates: Individuals, $\$ 24$ per year; institutions, $\$ 30$ per year. Copyright $\odot 1987$, Love Publishing Company. All rights reserved. Reproduction in whole or part without written permission is prohibited. Printed in the United States of America. Second class postage is paid at Denver, Colorado.

POSTMASTER: Send address changes to:

Love Publishing Company

Executive and Editorial Office

1777 South Bellaire Street

Denver, Colorado 80222

Telephone (303) 757-2579

EDITORIAL BOARD

\begin{tabular}{|c|c|}
\hline $\begin{array}{l}\text { Edward L. Meyen } \\
\text { University of Kansas }\end{array}$ & $\begin{array}{c}\text { Glenn A. Vergason } \\
\text { Georgia State University }\end{array}$ \\
\hline \multicolumn{2}{|c|}{$\begin{array}{l}\text { Richard J. Whelan } \\
\text { University of Kansas Medical Center }\end{array}$} \\
\hline $\begin{array}{l}\text { Stanley F. Love } \\
\text { Publisher }\end{array}$ & $\begin{array}{c}\text { Carolyn Acheson } \\
\text { Senior Editor }\end{array}$ \\
\hline
\end{tabular}

The requirement for data collection is not new in special education. For years we have used all manner and means of formal educational and psychological tests and informal observations to identify those to serve and, to a lesser extent, to evaluate the effectiveness of what we do. The problems with our traditional approach to measurement and data collection are many and have been chronicled elsewhere (see, for example, Galagan, 1985). They will not be repeated here. Rather, the focus of this article is an alternative approach to data-basing our special education problem-solving decisions: curriculum-based measurement.

Here, curriculum-based measurement first is defined and its decision-making purposes reviewed. Then, several advantages of this approach are discussed. Next, a framework for developing curriculum-based measurement systems is presented and applied to demonstrate how curriculum-based assessment methodology can be specified. Finally, a case study illustrating how a practitioner actually might employ the framework and design a curriculum-based measurement system for one specific student is presented.

\section{CURRICULUM-BASED MEASUREMENT}

\section{Definition}

The term curriculum-based measurement (CBM) has been applied to a variety of approaches for describing student progress (Deno, Marston, \& Tindal, 1986). As Tucker (1985) pointed out, however, the essential characteristic of all approaches to CBM is that "the measure of success in education is the student's progress in the curriculum of the local school" (p. 199). What makes CBM distinct from traditional psychoeducational measurement, then, is that the stimulus material that provides the occasion for student responses is the actual curriculum of the local school rather than a set of independent items or problems created by commercial test developers.

\section{Purposes}

CBM systems have begun to be applied widely for a variety of special education problem-solving purposes (see Tucker, 1985). First, CBM has been validated (Marston, Deno, \& Mirkin, 1984) and used (Germann \& Tindal, 1985) to create a data base from which screening and referral decisions are made. Quick, standardized samples of student performance on curricular materials can be used as a meaningful, efficient, objective tool for identifying pupils who 
are (a) academically discrepant from classroom peers (Shinn \& Marston, 1985) and (b) in need of in-depth assessment (Marston et al., 1984).

Second, CBM may provide the richest, most valid data source for developing effective programs. Systematic observations of performance in the curriculum provide the basis for formulating initial hypotheses about strategies for improving student growth (Howell, 1986). Additionally, ongoing assessment of students' curricular progress, in response to alternative instructional programs, has been demonstrated to effect much higher achievement levels than traditional approaches to program development (Fuchs, Deno \& Mirkin, 1984; Fuchs \& Fuchs, 1986-b).

Finally, CBM has been employed innovatively and effectively to (a) summatively assess the effectiveness of individual education programs in relation to specific exit criteria, and (b) evaluate the efficacy of special education programs in general along important dimensions such as time in program, type of handicap, and level of service (see Germann \& Tindal, 1985). Consequently, CBM provides a suitable and uniform data base for processing through the entire five-step problem-solving process constituting special education practice.

\section{Advantages}

The many advantages of using the local school curriculum as the stimulus material for measuring student performance have been reviewed elsewhere (see Deno, 1985). Three fundamental strengths are addressed here. Foremost, perhaps, is that CBM improves the match between testing and teaching. As demonstrated by Jenkins and Pany (1978) and Armbruster, Stevens, and Rosenshine (1977), the potential discrepancy between what is taught and what is tested can be considerable and can result in significant biasing of student achievement decisions. The correspondence between the test and the curriculum, known as curricular validity, has been shown to be an important element of effective instruction (see Fuchs \& Fuchs, 1986-a).

A second important advantage of CBM relates to the fact that the primary goal for most special education students is successful functioning within the mainstream curriculum. This means that special education student success must be defined in terms of competence in the mainstream curriculum. Relatedly, useful measurement indexes mainstream curricular growth, and CBM successfully addresses this requirement. It enables direct appraisal of the extent to which a student is performing successfully in the mainstream cur- riculum and whether sufficient improvement has accrued for the student's reintegration with mainstream peers.

Another key consideration in the selection of a measurement approach is the degree to which it communicates clearly among those who use the measurement data. Although psychoeducational testing represents the historical and predominant measurement strategy, it would be an overstatement to claim that all who communicate regarding student progress understand the derived scores from traditional tests. Finally, a related, important strength of CBM is that its direct measurement of progress within the curriculum used by mainstream teachers enables clear and direct communication between regular and special educators. This enhancement of communication applies to parents as well, because their children's performance in special education can be compared to the performance of mainstream children within the same curriculum. Mainstream curriculum, then, becomes the common standard against which all student performance is tracked for decision-making purposes.

\section{DEVELOPING CURRICULUM-BASED MEASURES: A FRAMEWORK}

CBM has been shown to provide an effective data base for special education problem solving, and compelling arguments can be made for why student performance in the curriculum of the local school ought to be the basis for measuring student achievement. Nevertheless, adopting a CBM approach raises formidable technical issues.

The technical issues related to adopting CBM are summarized by the question: How do we reliably measure student performance in the curriculum so that the data are valid for making special education problem-solving decisions? A framework for answering this question is presented in Tables 1 and 2. Table 1 is a matrix combining a set of measurement issues with factors that constrain the answers to those questions. Table 2 lists the questions that must be addressed when the issues in the matrix intersect with the related constraints to form matrix cells. Explication of this matrix proceeds in the following way. First, the constraints, issues, and currently available answers to the matrix questions are addressed for the "What" and "How" to measure components of the matrix. Then, for the "How to Use Data" portion of the matrix, the measurement issues and contraints with currently available answers to the matrix questions are specified. 
TABLE 1

Decision-Making Matrix

Technical Effectiveness Logistical

\begin{tabular}{|l|c|c|c|}
\hline $\begin{array}{l}\text { What to } \\
\text { Measure }\end{array}$ & T-1 & E-1 & L-1 \\
\hline $\begin{array}{l}\text { How to } \\
\text { Measure }\end{array}$ & T-2 & E-2 & L-2 \\
\hline $\begin{array}{l}\text { How to } \\
\text { Use Data }\end{array}$ & T-3 & E-3 & L-3 \\
\hline
\end{tabular}

Numbers are given to label cells. Corresponding questions are presented in Table 2.

\section{Constraints: "What" and "How" to Measure}

\section{Technical Adequacy}

Whereas some technical adequacy issues important in developing a CBM system are unique to the concerns of CBM, several issues are similar to the concerns of traditional, norm-referenced assessment. The relevant technical adequacy issues of traditional psychometric testing are the validity and reliability of the curriculum-based student achievement measure. Validity refers to the extent to which measurement data relate to the measurement purposes or improve decision making. Three relevant types of validity are criterion, content, and construct validity.

For a measure to demonstrate strong criterion validity, scores should correlate highly with other data that are deemed important. For a reading achievement measure, for example, to have criterion validity, it should correlate with technically adequate standardized tests of reading, teacher placement in the curriculum, or placement in special reading programs. If we explore "reading aloud from text" as a potential behavioral indicator of reading proficiency, low scores on textual material should be associated with poor performance on global, norm-referenced reading tests, and high scores should be associated with good performance on the global, norm-referenced tests.

Content validity is dependent upon the adequacy with which a specified domain of content is sampled. For example, measuring "reading aloud from text" would possess content validty if teachers agree that their goal is to teach students to read text aloud proficiently.

Finally, construct validity represents the extent to which measures correlate in expected ways with other measures or are affected in predictable ways by experimental treatments. Once a domain of behaviors is specified, along with the ways in which those behaviors relate to one another, experimental evidence is sought to confirm or disconfirm that those behaviors actually relate to one another as hypothesized.

A second technical adequacy issue that applies to CBM is reliability including test-retest reliability, alternate-form reliability, and interscorer agreement. Test-retest reliability is illustrated in the following example. John makes the most errors of anyone in his reading group when reading words from a third-grade word list on Monday; on Wednesday, when all read the same list again, we can expect his performance to be similar. Test-retest reliability is the extent to which a set of students' relative scores are alike on two testings.

A second form of reliability, alternate-form reliability, is highly relevant for CBM when monitoring progress requires repeated testing with a different test form at each measurement session. Alternate-form reliability is the extent to which the relative scores of a group of students are similar on alternate test forms. A third type of reliability, interscorer agreement, refers to the extent to which a group of students' performances are scored alike by independent examiners. All forms of reliability indicate the extent to which scores on a test are free from error and represent a student's "true score."

In addition to these tradtional technical concerns, CBM, wherein student performance is monitored over time, requires consideration of a number of other technical issues. One of these is the reliability of the trend or slope of the data, which is indicative of changing student achievement across days in school. Other technical concerns include: (a) the amount of intra-individual variability from day to day or week to week, (b) the degree to which the measurement data are linked directly to the goal specified on the IEP, and (c) the reliability or consistency of teachers' interpretations of data.

\section{Instructional Effectiveness}

The ultimate purpose of a CBM system is to solve problems. Therefore, in addition to technical concerns, selection among measurement and evaluation components should re- 


\section{TABLE 2}

\section{Questions Posed in the Decision-Making Matrix}

\section{Technical}

T-1. What to measure: What behaviors clearly index growth and are responsive to the effects of instruction?

T-2. How to measure: What measurement procedures generate reliable and valid data that are sensitive to short- and long-term growth?

T-3. How to use data: How should the data be summarized, analyzed, and interpreted to ensure reliable and valid decision making?

\section{Effectiveness}

E-1. What to measure: Does measuring different behaviors relate to different achievement outcomes?

E-2. How to measure: Do different measurement procedures result in different rates of student improvement?

E-3. How to use data: What data-based decision rules result in more successful programs?

\section{Logistical}

L-1. What to measure: What behaviors are readily accessible for repeated measurement?

L-2. How to measure: What measurement procedures are most efficient and least intrusive?

L-3. How to use data: What data utilization procedures are most efficient and cost-effective?

flect the effects those elements have on teacher decision making and student achievement. Instructional effectiveness concerns have, in fact, been shown to be relevant. A metaanalysis of the effects of CBM on student achievement indicated that procedural differences in CBM produce differential student growth (Fuchs \& Fuchs, in press-b). Instructional effectiveness, consequently, is included in the decision-making matrix.

\section{Logistical Feasibility}

A major teacher concern is that CBM may be too time consuming (Wesson, King, \& Deno, 1984). In research conducted in a rural special education cooperative (Fuchs, Wesson, Tindal, Mirkin, \& Deno, 1981), elementary resource teachers initially spent an average of $2 \frac{1 / 4}{4}$ minutes preparing for, administering, scoring, and graphing one curriculum-based measure for one student. Multiplied across a full caseload of students, this figure represents a large portion of teacher time. In designing a feasible measurement system, then, one must make logistical changes to reduce teacher and student time in measurement. Consequently, logistical feasibility also is incorporated within the decisionmaking matrix of a constraint on determining CBM procedures.

\section{Measurement Issues: "What" and "How" to Measure}

\section{What to Measure}

In developing an adequate set of CBM procedures, the first issue to address is selection of a behavior to be measured. In reading, for example, students can be observed reading isolated words aloud or silently, reading text aloud or silently, answering questions based on text reading, decoding nonsense words, completing cloze passages, and completing worksheets. In spelling, students can be measured writing from dictation, editing word lists, recognizing correct alternatives, writing paragraphs, and doing various "spelling" worksheets. Before curriculum-based data can be collected, the specific behaviors that are vital, global indicators of student academic growth must be identified. 


\section{FIGURE 1 \\ Decision Flow for Academic Domains of Reading and Spelling}

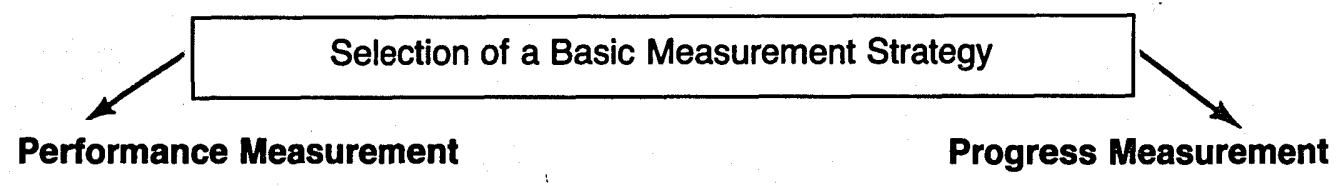

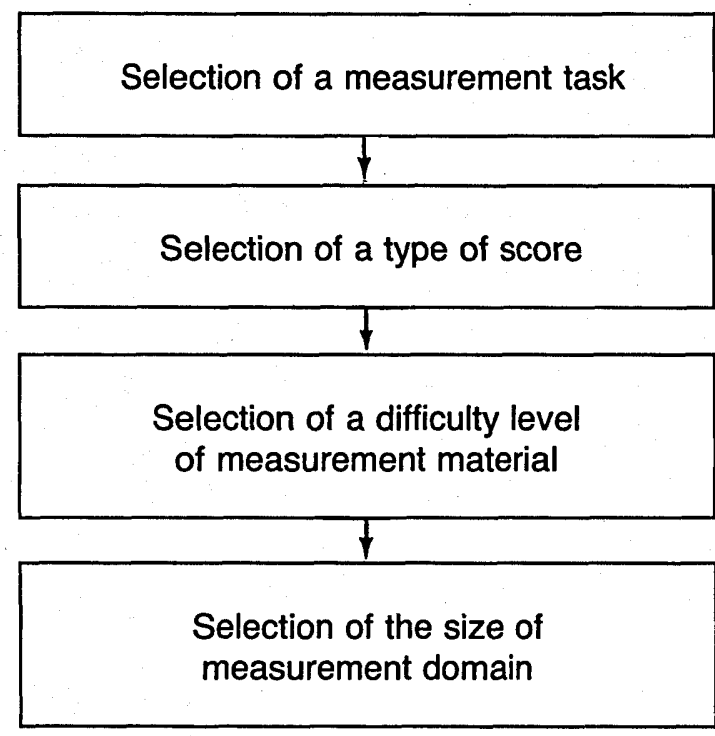

How to Measure

Decisions constituting "How to Measure" vary by academic domain. Figures 1 and 2 illustrate the decision flows for reading and spelling, and for written expression, respectively. The following discussion briefly describes each decision referenced in Figures 1 and 2.

Selection of a basic measurement strategy for monitoring student progress is an essential decision in designing a measurement system. Two strategies are performance measurement and progress measurement (Deno \& Mirkin, 1977). Performance measurement provides information on how a student's behavior changes on a task of constant difficulty. In performance measurement, increases in fluent performance on equivalent forms of the task should represent growth or achievement. For example, a teacher might decide to measure a student's performance on reading aloud from a fourth-grade reader. Each day the teacher would select randomly a passsage to measure student performance and ask the student to read aloud for 1 minute. With this strategy the student's graph might display the number of words correct and the number of errors per day during 1 minute of reading from the fourth-grade text.

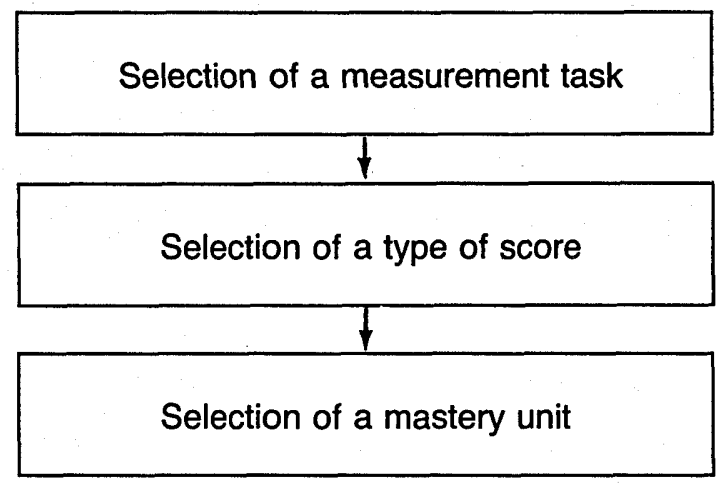

FIGURE 2

Decision Flow for Academic Domain of Written Expression

Selection of a measurement task

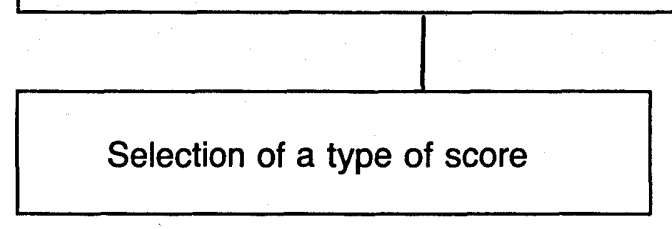

As illustrated in the work of Deno and Mirkin (1977), progress measurement, a second strategy, involves monitoring student mastery through a curriculum over a period of time. In progress measurement, a sequence of objectives is specified and a criterion of mastery is established for each objective. Mastery of objectives then is assessed frequently to monitor student progress. For instance, a teacher might establish a series of phonics skills as the sequence of objectives to be mastered. Then the teacher might determine that 
a performance standard of reading $\mathbf{5 0}$ words per minute correctly with no more than two errors is the criterion of mastery to be met before a student can progress to the next objective. The student's graph, therefore, would display objectives mastered per time unit, and improved progress would be indicated by an increased rate of mastery through the objectives.

Performance and progress measurement are different in two essential ways:

1. In performance measurement, the measurement task is sampled constantly from the same pool of material; in progress measurement, the measurement task changes each time the student masters a segment of the curriculum;

2. In performance measurement, the goal is to describe changes in performance on one specific level of material; in progress measurement, the object is to describe the rate of progress through a series of tasks. Table 3 summarizes this concept.

Within each measurement strategy one must select a score (correct rate, percentage correct, or incorrect rate) to employ in analyzing the measurement sample. Depending on the level of student behavior, one might want to score small units of behaviors, such as letter sequences spelled correctly, or large units of behavior, such as words or even sentences spelled correctly. Depending on teacher time available to score, one might want to analyze types of phonetic errors or just number of errors.

Within performance measurement two additional decisions remain. First, one must determine at what difficulty level measurement will occur (e.g., at instructional level, at age/grade-appropriate material). This difficulty level remains constant as the student's proficiency changes. One also must select the size of the measurement domain. That is, given a difficulty level of material, one must determine the size of the material pool from which frequent measurement tasks will be sampled (from several grade levels of material, within one grade level of material, within one unit of material, etc.).

Within progress measurement, one additional decision remains. A unit of mastery (pages, stories, units, books in reading; words, lists, units, books in spelling) must be determined. Often this is problematic because curricula are not designed so that mastery units are equivalent-a requirement for a technically adequate measurement system.

Once the basic measurement is established, measurement frequency must be determined. Will measurement occur daily, twice per week, weekly, monthly? Further, one must establish student mastery criteria. Within progress measurement one must determine mastery criteria for each step or objective within the hierarchy of skills. Within performance measurement one must determine criteria that specify when acceptable performance has been met on the long-range goal or outcome behavior.

Three remaining decisions relevant to "How to Measure" involve (a) procedures for generating test samples, (b) procedures for administering test, and (c) determining duration of test samples-whether each measurement sample will involve a constant time (e.g., a duration of 30 seconds, 1 minute, 3 minutes) or fixed number of stimuli (e.g., 20 words, 30 words). These parameters specify the mechanics of measurement. The mechanics must be outlined and held constant if the measurement data are to be interpreted meaningfully. Generation of test samples refers to how the many equivalent measurement samples will be created. Administration of test samples relates to the standard procedures (directions, setting, schedule) employed in administering the measures. Duration of test samples addresses the length of time to administer a test.

TABLE 3

Differences Between Progress and Performance Measurement

\begin{tabular}{|l|l|l|}
\hline Type of Measure & $\begin{array}{l}\text { Difficulty Level of } \\
\text { Measurement Material }\end{array}$ & Goal \\
\hline Performance & remains constant & $\begin{array}{l}\text { to improve performance on } \\
\text { same level of material }\end{array}$ \\
\hline Progress & $\begin{array}{l}\text { increases througha } \\
\text { skills sequence }\end{array}$ & $\begin{array}{l}\text { to improve rate of progress } \\
\text { through increasingly more } \\
\text { difficult material }\end{array}$ \\
\hline
\end{tabular}




\section{Current Answers: "What" and "How" to Measure}

Because CBM is a generic concept, various CBM systems have been developed and integrated into teaching systems (cf., Deno, Marston, \& Tindal, 1986). Each of these systems has answered somewhat differently the questions of what and how to measure. In providing an example of how these questions might be answered, results of research and development of CBM through the Institute for Research on Learning Disabilities at the University of Minnesota, focusing on the areas of reading, spelling, and written expression, are used. That research is described elsewhere (cf., Deno, 1985; Deno, Marston, \& Mirkin, 1982; Deno, Mirkin, \& Chiang, 1982). Guidelines for answering what should be measured and how measurement should occur, derived from that research, are summarized below.

\section{Reading}

What to Measure: Reading aloud from text passages randomly selected from one level of the school's basal reading series (elementary) or a subject matter text (secondary).

\section{How to Measure and Score Reading Performance}

1. Select one of the reading passages that corresponds to the appropriate level for the student's long-range goal.*

2. For each passage there are two forms-an unnumbered copy for the student and a numbered copy for the teacher. Put the student copy in front of and facing the student.

3. Put the teacher copy in front of and facing yourself.

4. Say to the student: "When I say 'start,' begin reading aloud at the top of this page. Try to read each word. If you wait for a word too long, I'll tell you the word. You can skip words that you don't know. At the end of one minute, I'll say 'stop."' (Give student 3 seconds before supplying words.)

5. Turn on the stopwatch as you say "start."

6. Follow along on your copy, circling with a pencil incorrectly read words (omissions, substitutions, mispronunciations, insertions).

\footnotetext{
*Ask regular classroom teachers what the expected curricular level of average students of the same age and grade as the target student will be at the time of the next annual review. For additional information on placement criteria, see Mirkin, Deno, et al. (1981).
}

7. At 1 minute, say "stop" and turn off the stopwatch.

8. Place a slash after the last word read.

9. Count the number of words correct and the number of errors. (The teacher copy lists the number of words per line.)

10. Record both correct and incorrect scores on an equalinterval graph labeled "Number of Words Read Aloud from Text Passages."

11. Repeat steps 1-10 at least twice weekly.

\section{Spelling}

What to Measure: Writing words or letter sequences (White \& Haring, 1980) dictated from a constant level of the school's spelling curriculum or basal reading series.

\section{How to Measure and Score Spelling Performance}

1. Find the spelling list that corresponds to the appropriate level for the student.*

2. Give the student a pencil and a response form with his/her name written on it.

3. Say to the student, "I am going to read some words to you. I want you to write the words on the sheet I just gave you. Write the words in the first column, and then go to the top of the second column. I'll give you 10 seconds to spell each word. When I say the next word, try to write it even if you haven't finished the last one."

4. Say, "Let's begin," as you start the stopwatch.

5. Begin, dictating each word in order. In the case of homonyms, a short sentence incorporating appropriate use of the word should be presented following pronunciation of the word.

6. Present each word upon the student's completion of the previous word. After 10 seconds present the next word even if the student has not completed the previous word.

7. Dictate words for 2 minutes. If the student is near completion of a word and the time is up, allow him/her to finish that word. Do not present any new words in the last 3 seconds of the test.

8. Count the number of correctly spelled words or correct letter sequences.

9. Record correct scores on an equal-interval graph labeled "Number of Words Correct/Incorrect" or "Number of Letter Sequences Correct/Incorrect."

10. Repeat steps 1-9 at least twice weekly. 


\section{Written Expression}

What to Measure: Writing words or letters in stories in response to a story starter or topic sentence.

\section{How to Measure and Score Written Expression Performance}

1. Give the child a pencil and a response form. (Story starters may be individually or group administered.)

2. Give the student the following instructions. "Today I want you to write a story. I am going to read a sentence to you first, and then I want you to write a short story about what happens. You will have 1 minute to think about the story you want to write and then have 3 minutes to write it. When I say 'begin', start writing."

3. Time the student as he/she writes for 3 minutes.

4. When 3 minutes have elapsed, tell the student to stop writing.

5. Count the total number of words or letters written in the composition, including words spelled incorrectly. Count all personal nouns and names. Do not count numbers.

6. Record the total number of words or letters written by the student on an equal-interval chart labeled "Number of Words or Letters Written."

7. Repeat steps 1-6 at least twice weekly.

As is evident in this description of the Minnesota CBM procedures, the measurement procedures are standardized, even as the stimulus items for the test are generated from the local school curriculum. These standardized measurement procedures produce reliable data that also have demonstrated validity for making special education programming decisions (cf., Germann \& Tindal, 1985; Marston \& Magnusson, 1985).

\section{Measurement Issues: "How to Use Data"}

Evidence suggests that teachers who collect student performance data do not necessarily use those data to make instructional decisions (Baldwin, 1976; White, 1977), and that systematic procedures for interpreting student performance data appear to be an important dimension of an effective CBM. In a meta-analysis, Fuchs and Fuchs (1986b) found that the effectiveness of CBM was enhanced when teachers used a systematic data utilization strategy. For that reason, careful attention should be given to how CBM data will be recorded, graphed, and interpreted. The decision-making matrix presented in Table 1 is used as a framework for considering data utilization strategies with CBM.

\section{Charting Student Progress}

A feature common to virtually all approaches to CBM is that student progress over days is displayed visually. The number of charting options is great (Deno \& Mirkin, 1977). The procedures described here focus on those selected for use with the CBM systems developed at the University of Minnesota.

A first decision that has to be made is whether to chart mastery of successive levels of the curriculum (progress measurement) or to chart change in proficiency on a level of constant difficulty (performance measurement). For progress measurement, cumulative units of curriculum per time unit are graphed. For performance measurement, changing levels of performance on samples from the same material pool per time unit are graphed. Few alternative procedures are available within each measurement format. Further, little evidence supports the superiority of any one graphing procedure. Given the lack of research data, the technical, effectiveness, and logistical constraints influencing the decision of what and how to graph progress are grouped below and discussed by basic measurement strategy.

A critical problem in progress measurement is the lack of equal intervals to represent curriculum units along the vertical axis. Therefore, an essential rationale for employing a particular graphing convention within progress measurement is how it resolves this problem.

Deno and Mirkin (1977) advocated a graphing procedure wherein mastery units along the vertical axis are plotted so that the units are spaced in accordance with the mastery time demonstrated by average students. The feasibility of this approach has been demonstrated by Peterson, Heistad, Peterson, and Reynolds (1985). The graph is organized so that for the average student the level of progress is one-toone; for each time unit the average student is expected to master the number of pages or stories designated for that period. Average rate of progress through the curriculum, then, is depicted by a diagonal line from the lower left corner to the upper right corner of the graph.

A problem inherent in the progress measurement graph is that curricula are not designed so that the mastery units sequentially plotted at these equal intervals actually represent equivalent segments of the curriculum. For example, if a story is more difficult than the one it follows, the second story represents a larger unit of mastery even though the two stories were plotted as equal units. 
Although no available research addresses the relative effectivness or logistical feasibility of alternative mastery units, selection of a mastery unit can be based on technical considerations. Selection of a very small mastery unit should increase the probability that units on the vertical axis will represent equal intervals. Pages are much more likely to be equivalent mastery units than are stories, clusters of stories, or entire books.

An additional advantage in selecting a very small mastery unit is that it virtually ensures that the data will be sensitive to student change. With pages as the mastery unit, students easily can register growth. In contradistinction, if books are the unit of mastery, the measurement format might be insensitive to student improvement because the pupil would have to gain much proficiency before mastering an entire book and registering any growth. Therefore, both of these technical considerations - approximating equivalent mastery units and ensuring sensitivity to student growth-support the use of a relatively small mastery unit within a measurement and evaluation system.

With respect to additional graphing conventions within progress measurement, logistical and instructional considerations support students graphing their own data. Once students are competent graphers, this procedure should reduce teacher time and therefore improve the feasibility of frequent measurement. Additionally, Frumess (1973) demonstrated that students who scored and graphed their daily reading performance achieved significantly better than students who only scored their performance.

Within performance measurement, the relative merits of equal-interval and semi-logarithmic paper have been explored. In two crossover studies. Brandstetter and Merz (1978) compared the reinforcement value of semi-log graphs and linear graphs with the reinforcement value of raw scores. In the first study, reading gains made while charting on linear graphs were significantly greater than gains made while recording raw scores. In the second study, the difference between charting on semi-log graphs and recording raw scores was not significant. Because the children in both studies were neither randomly assigned nor similar to each other, however, valid comparisons cannot be made between the effectiveness of the two types of graphs.

Marston (in press) compared the prediction capabilities of both types of charts. After calculating the performance slope for each of 82 elementary students who were measured weekly over 7 weeks, predictions of student scores for weeks 8,9 , and 10 were determined. Actual student performance for weeks 8,9 , and 10 then was compared to the predictions made with equal-interval and semi-logarithmic charts. For the academic areas of reading, spelling, and written expression, predictions were significantly better on the equal-interval graphs. Therefore, given that teachers may prefer equalinterval graphs and find them easier to interpret and share with students, currently available research on graphing, albeit scant, seems to indicate the use of equal-interval graphs.

\section{Data Interpretation}

Once student performance data have been collected and graphed, the educator must summarize and interpret these data to determine whether the instructional program appears effective or whether that program should be changed. Two approaches to data summarization and interpretation are goal-oriented and program-oriented analyses.

In goal-oriented data analysis, the objective is to ensure that a student's performance reaches a prespecified goal by a certain date. This goal may represent any reasonable performance level selected by the teacher. Or, in a more systematic fashion and in consonance with the principles of normalization (Wolfensberger, 1972), this goal may be a performance level (a) commensurate with a student's mainstream peers, or (b) representing a reduced discrepancy between the student's current performance and his or her age/grade appropriate level.* This goal, designated the "static aim" (Liberty, 1972, 1975), is marked on the graph with an $\mathrm{X}$ at the intersection of the desired performance level and the anticipated attainment date. Then a line of desired progress, the "dynamic aim," connects the student's baseline median score with the static aim on the graph.

Throughout the delivery of instruction, data summarization consists primarily of determining median performance within intervention periods. Data interpretation consists of application of some form of the following rule: If on $\mathrm{N}$ consecutive days $(2,3$, or more), student performance data fall below the dynamic aimline, the program is judged ineffective and should be changed. Two possible consequences are: (a) A new aimline is drawn on the graph, parallel to the old aimline but originating from the intersection of the middle day on which performance was inadequate and the median performance level of those inadequate data points,

\footnotetext{
*Ask regular classroom teachers what the expected curricular level of average students of the same age and grade as the target student will be at the time of the next annual review. For additional information on placement criteria, see Mirkin, Deno, et al., (1981).
} 
or (b) the student's program is changed. A change in the program is designated on the graph with a vertical line running through the data on which the program change was introduced.

In program-oriented data analysis, the student performance level and attainment date may be specified but are not essential to data utilization. Instead, the directive is to test changes in a student's program frequently and systematically, to move the student's performance toward the highest possible rate of improvement. One assumes that only by implementing an unending series of program changes and by comparing the effects of those program changes on a student's performance can an effective individual program emerge (Deno \& Mirkin, 1977). Therefore, program changes are introduced regularly and are treated as experimental hypotheses to be tested by observing their effect on a student's performance.

\section{Data Summarization}

In goal-oriented analyses, drawing trend lines through actual student progress is the primary method of summarizing student performance. By contrast, data summarization in a program-oriented analysis is more comprehensive. Data interpretation is directed toward judging the effectiveness of a program or experimental treatment by comparing student performance across different interventions.

The four indices of performance are: (a) the median, a measure of central tendency representing the score that falls at the 50th percentile; (b) the trend, a line of best fit through the data points, which indicates how fast and in what direction student performance is changing; (c) the shift up or down on the first day of intervention (i.e., the size and direction of the difference between the last data point of the previous intervention and the first data point of the current program); and (d) the variability or "bounce" (Pennypacker, Koenig, \& Lindsley, 1972) of the data points around the trend line. These indices are compared across phases of a program to determine whether a program change has improved student performance. Changes in median, trend, step up/down, or variability among phases are inspected and interpreted to formulate decisions about the effectiveness of programs.

\section{Constraints and Current Answers: "How to Use Data"}

\section{Technical Considerations}

In exploring the technical strengths of goal- and programoriented data summarization and interpretation, two relevant considerations are (a) accuracy of judgments and (b) interjudge agreement. With respect to the accuracy of judgments, goal-oriented analysis appears to be stronger (Tindal, Wesson, Mirkin, Deno, \& Fuchs, 1982). Ten teachers in a rural special education cooperative were assigned randomly and then trained to use either a goal-oriented or programoriented procedure to analyze their students' graphs. Midway through the study each teacher crossed over to the other data analysis condition. Results indicated that, by the end of the study, teachers summarized data more accurately with the goal-oriented analysis rules $(47 \%$ vs. $12 \%$ correct summarizations), and the timing of changes in students' programs was more accurate with the goal-based rules $(70 \%$ vs. $33 \%$ correctly timed changes).

With respect to interjudge reliability, program-oriented analysis may be stronger. In the same study (Tindal et. al., 1982), teachers' judgments with the program-oriented analysis rules were more reliable for both when program changes should be introduced ( $76 \%$ vs. $62 \%$ agreements) and when program changes were producing student growth ( $88 \%$ vs. $74 \%$ agreements).

The technical superiority of one data summarization/utilization method over the other, therefore, has not been established clearly. Program-oriented analysis appears to be more reliable and goal-oriented analysis more accurate. Certainly, differences in the results were larger and more dramatic for the reliability contrasts; goal-oriented accuracy was an average 3 times greater. On the basis of these results, one might conclude tentatively that each data utilization method has some technical strength. Perhaps the goal-oriented method renders more correct, and therefore technically superior, decisions.

\section{Effectiveness Considerations}

Scant evidence exists for the superiority of either data utilization procedure in producing greater student gains. Available studies have contrasted the relative effectiveness of monitoring short-term objectives using weekly aimlines with monitoring long-term objectives using program-oriented methods (Mirkin, Fuchs, Tindal, Christenson, \& Deno, 1981; Tindal, Fuchs, Christenson, Mirkin, \& Deno, 1981). Results indicated that teachers believed they were more effective in the short-term objective conditions, even though there actually were no student performance differences.

Perhaps the only piece of evidence directly contrasting 
goal- and program-oriented methods supports the instructional effectiveness of a goal-oriented analysis because of its effect on teacher behavior. Tindal et al. (1982) demonstrated that teachers more accurately judged effective interventions when they applied goal-oriented analysis procedures ( $100 \%$ vs. $80 \%$ accurate judgments).

\section{Logistical Considerations}

Goal-oriented analysis also appears stronger for two logistical reasons. First, data summarization is less time consuming; it entails the computation of one rather than four statistics. Second, over two training sessions in the study described above (Tindal et al., 1982), teachers were more accurate in the goal-oriented analysis group ( $79 \%$ vs. $68 \%$ correct decisions). Therefore, goal-oriented analysis methods appear to be more feasible because they are less time consuming during both training and day-to-day implementation.

Nevertheless, evidence suggests that teachers may prefer a combination of the two data utilization methods. Fuchs, Wesson, Tindal, Mirkin, and Deno (1982) found that teachers preferred the goal-oriented approach for (a) monitoring progress toward IEP goals, (b) the ease of its use, (c) its efficiency, (d) a guide concerning when to change a student's instructional program, (e) the ease with which it could be described to parents and other teachers, (f) its more adequate representation of student performance, and (g) its overall usefulness. The program-oriented approach was preferred by most teachers only as a guide for what to change in a student's instructional program.

When asked to name the data utilization system of their choice, one-half of the surveyed teachers indicated that they preferred to use a combination of the two approaches. Therefore, despite the teachers' overwhelming preference for goaloriented evaluation, many chose a combination of the two. This finding may be attributed to the fact that goal-oriented evaluation addresses the question of when, not what, to change in a student's program and that teachers preferred program-oriented evaluation for determining what to change in an educational plan. For handicapped children, the question of what to change may be especially problematic. This may have led some teachers to conclude that a combination of the two strategies is optimal.

A strong experimental contrast of the two data utilization strategies, one with dramatic and persuasive results, currently is not available. Nevertheless, evidence suggests that a goal-oriented analysis may be more technically adequate, more feasible, more efficient, and more instructionally useful. Given these results, along with teachers' preference for a combination of the two data utilization approaches, a combined data utilization method that borrows more heavily from the goal-oriented approach is recommended.

In this approach (Mirkin, Deno, et al., 1981), teachers draw the dynamic aimline on the graph. Then a trendline based on 7 to 10 student performance data points is graphed and compared to the slope of the dynamic aimline. If the student performance slope is less steep than the aimline, a program change is introduced. Logistically, this data utilization rule is facilitated by the availability of computer software packages whereby teachers can enter student performance data and access a student graph with aimline and a decision concerning whether a program change is indicated.

In a significant experimental study comparing the effectiveness of teachers using CBM procedures to those not using CBM procedures, this combination strategy was employed (Fuchs, Deno, \& Mirkin, 1984), with significant achievement benefits accruing to students taught with CBM. Therefore, tentative support for the value of this combined CBM data-utilization approach is provided.

\section{USING CBM TO DATA-BASE A STUDENT'S PROGRAM: A CASE STUDY}

\section{CBM Decision Sequence}

As presented above, the process of formulating a CBM system entails a 10-step sequence. Each of these decisions is reviewed here, illustrating how a special education teacher, Mrs. R., applied the decision-making matrix to design a CBM strategy for one specific student, Michael, for the purpose of formatively developing an effective instructional program.

\section{What to Measure: Selection of a Behavior}

Consistent with the recommended CBM procedures, Mrs. $R$. decided that she would measure Michael's reading aloud from text. Reading aloud from text increases developmentally and demonstrates both construct and criterion validity (see Deno, Mirkin \& Chiang, 1982). Measuring reading aloud in context provides rich information for making sound program improvement decisions and is easy to measure relative to other reading behaviors (see Mirkin, Fuchs, \& Deno, 1982). 


\section{How to Measure: Selection of a Basic Strategy}

Mrs. R. decided that her basic measurement strategy would be performance measurement. She decided to select one level of difficulty for the reading selections on which she would measure Michael's progress with a goal of improving Michael's performance on that material. Because neither progress nor performance measurement had a clear advantage, Mrs. R. chose performance measurement because of personal perference.

\section{How to Measure: Selection of a Score, a Difficulty Level, and a Measurement Domain}

Mrs. R. chose to record the number of correctly and incorrectly read words as the scores she would monitor. She selected level 2 of the SRA Series as the material from which she would draw selections for measuring Michael's reading aloud in context because it represented a mid-range difficulty for Michael. (He initially read 55 words per minute correct with no more than 11 errors.) She decided to monitor correct and error scores because the correct scores represent technically adequate data and the error scores would provide supplemental information for generating instructional hypotheses (see Mirkin et al., 1982).

Having decided on correct and error scores, as well as Level 2 of the SRA series, Mrs. R. was ready now to determine what the size of the measurement domain would be. She decided on a mid-sized domain, all of Level 2, because it was likely to render data with relatively low variability and with an acceptable slope; further, it probably would remain an appropriate difficulty level for Michael over the entire school year (see Fuchs, Tindal, \& Deno, 1984).

\section{How to Measure: Selection of a Measurement Frequency and a Sample Duration}

Given the associated technical, logistical, and effectiveness constraints (see Mirkin et al., 1982), Mrs. R. selected a schedule of a least twice weekly and a sample duration of 1 minute.

\section{How to Measure: Selection of a Criterion of Mastery or Goal}

Mrs. R. decided on a mastery criterion of 80 words correct with no more than 8 errors (a 90\% accuracy criterion). This criterion of mastery or goal represented to Mrs. R. a reasonable but ambitious amount of improvement for Michael. Additionally, it fell close to the recommended rates (see Fuchs, Fuchs, \& Deno, 1982; Mirkin et al., 1982).

\section{How to Measure: Selection of a Procedure for Generat- ing Test Samples}

Mrs. R. used a random selection procedure for generating test samples, wherein she (a) selected passages from the level representing the annual goal and wrote on equalsize slips of paper the number of each of the pages in stories that did not have excessive dialogue, indentations, or unusual pronouns; (b) put the slips of paper into a drawbag and shook it; (c) randomly picked a slip of paper; and (d) had the student begin reading on the page number shown on the slip of paper (see Mirkin, Deno, et al., 1981).

\section{How to Measure: Selection of Administration and Scoring Procedures}

Once the practitioner has defined a measurement system, only a few alternatives exist for administering and scoring tests. The two primary considerations in choosing among alternatives are: (a) technical-maintaining consistent procedures across testing occasions, and (b) logistical - designing efficient administration and scoring procedures. Mrs. $R$. used the CBM procedures described for reading that were presented above (see Mirkin, Deno, et al., 1981, for rationale).

\section{Specification of a Goal and Objective Form}

Having specified "What to Measure" and "How to Measure," Mrs. R. was ready to complete the following Goal and Objective Form.

Goal In 19 weeks ___ when presented

(\# school weeks until year's end)

with stories for 1 minute from Level 2-SRA Series, (Level \#, series)

$\frac{\text { Michael }}{\text { (student's name) }}$ will read aloud $\frac{80}{\text { (words per minute correct) }}$
with no more than 6 errors.


Objective Each successive week, when presented with a random selection for 1 minute from Level 2-SRA Series,

(same level \# and series as above)

the student will read aloud at an average increase of

2.6 words per week and no increase in errors.

(\#)

\section{Specification of a Measurement System Form}

To summarize further the decisions Mrs. R. made, she next completed the Measurement System Form.

Behavior: reading aloud in context

Frequency: at least twice weekly

Duration of Test: 1 minute

Difficulty Level: Level 2-SRA Series

Size of Domain: all of Level 2

Test Administration Procedure: see description

Scoring Procedure: see description

\section{How to Use Data}

Having specified what and how she would measure, Mrs. R. had to determine how she would use the data she collected. The first decision she made was to graph the data on equal-interval paper. Figure 3 displays Michael's graph with "Words Read Per Minute" on the vertical axis and "Months" (and school days within them) on the horizontal axis. The first three data points on this figure indicate Michael's baseline performance (A) on the Level 2 material. The vertical lines following these baseline data indicate the introduction of new dimensions into Michael's reading program. These program dimensions are labeled A, B, and C at the top of the vertical lines. The large $X$ on the right side of the graph indicates the mastery criterion or goal that Mrs. R. set for Michael. The diagonal line from the baseline median to the $\mathrm{X}$ is Michael's dynamic aimline, depicting the rate of progress Michael would have to exhibit to meet his goal as anticipated.

With this graph established, Mrs. R. could plot data points and easily see, on any given day, how Michael's performance compared to his dynamic aim, or the level at which he had to perform to reach the long-term goal. Then Mrs. $R$. adopted the combined data utilization rule described previously: If a trendline drawn through the last 7 to 10 data points was greater than or equal to the slope of the dynamic aimline, she maintained the student's program; if the trendline was less than the aimline slope, she introduced a change into Michael's program. With the introduction of the third program change, Michael's performance improved dramatically over his previous performance.

Using the decision framework and procedures described here to formulate a CBM system, Mrs. R. established a close connection between the instruction she provided Michael and the way she measured and evaluated his progress. With this measurement and evaluation system, Michael's educational program and progress toward goals was evaluated formatively. In response to measurement data, Michael's program was modified throughout the school year to improve his reading achievement.

\section{SUMMARY AND CONCLUSIONS}

CBM is a data-based strategy by which special education problems can be solved and by which decisions about referral, program development, and summative evaluation can be formulated. With CBM, assessment demonstrates strong curricular validity, addresses the overall special education goal for competence within mainstream curricula, and is easily understood. Nevertheless, designing a comprehensive, reliable, and valid CBM system that simultaneously is instructionally effective and logistically feasible can be difficult. A decision-making framework, employing technical, instructional, and logistical considerations for determining what to measure, how to measure, and how to use data, can systematize the process of specifying CBM systems and result in more adequate measurement, along with improved special education problem solving.

The procedures selected and described here may incorporate answers based on the most currently available empirical investigation, but further unresolved issues represent fertile territory for additional research to illustrate many sound CBM procedures. In addition to facilitating the design of measurement systems, the decision-making matrix represents a useful framework for conceptualizing useful research questions in the area of curriculum-based measurement.

\section{REFERENCES}

Armbruster, B.B., Stevens, R.G., \& Rosenshine, B. (1977). Analyzing content coverage and emphasis: A study of three curricula and two tests. (Technical Report N26). Urbana: University of Illinois, Center for the Study of Reading.

Baldwin, V. (1976). Curriculum concerns. In M.A. Thomas (Ed.), Hey, don't forget about me. Reston, VA: Council for Exceptional Children. 


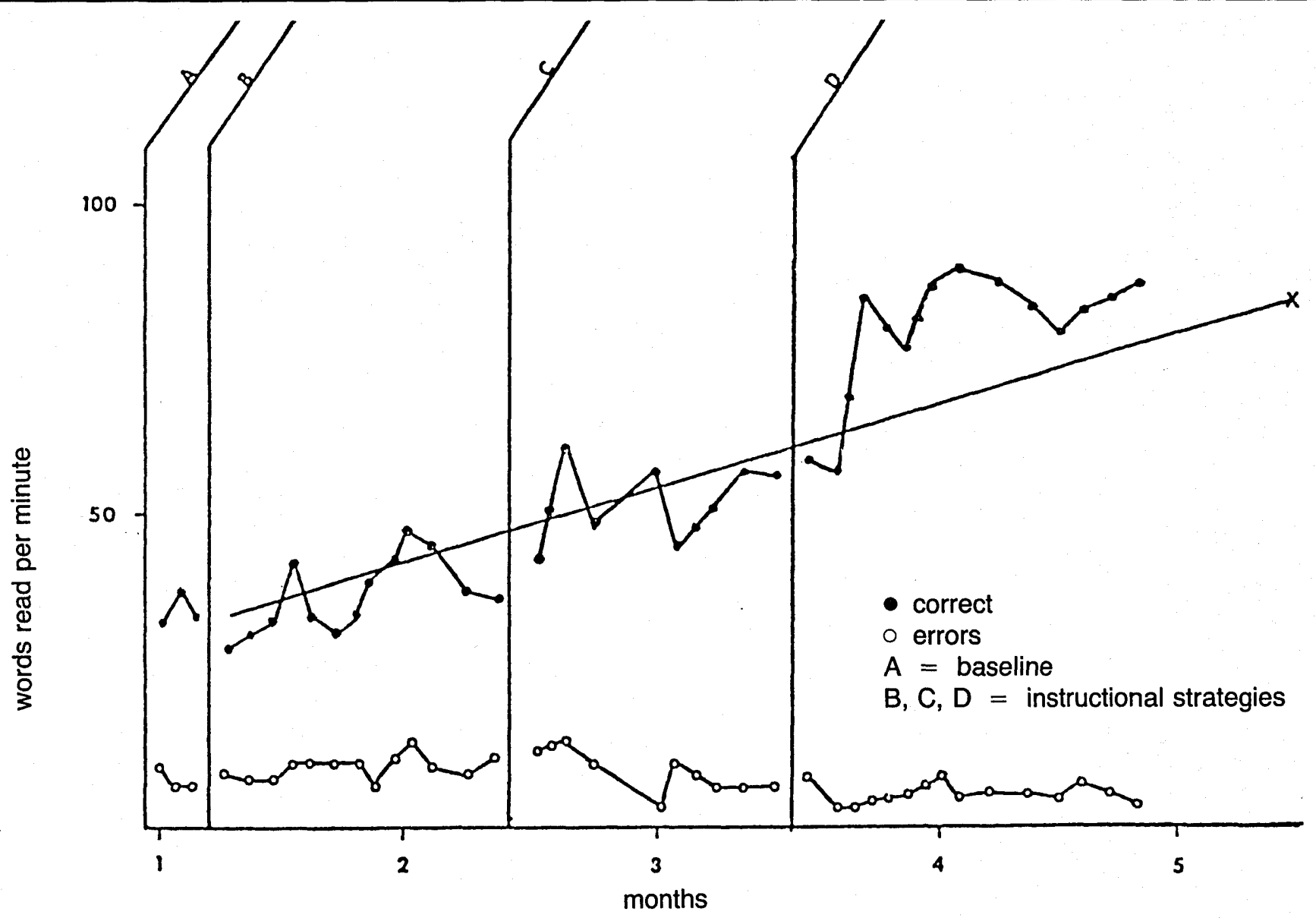

FIGURE 3

Example of Correct Words and Errors Per Minute by Michael Across Time and Using Three Instructional Strategies

Brandstetter, G., \& Merz, C. (1978). Charting scores in precision teaching for skill acquisition, Exceptional Children, 45(1), 42-48.

Deno, E.N. (1970). Special education as developmental capital. Exceptional Children, 37(3), 229-237.

Deno, S. (1985). Curriculum-based measurement: The emerging alternative, 52(3), 219-231.

Deno, S., Marston, D., \& Mirkin, P. (1982). Valid measurement procedures for continuous evaluation of written expression. Exceptional Children, 48(4), 368-371.

Deno, S., Marston, D., \& Tindal, G. (1986). Direct and frequent curriculum-based measurement: An alternative for educational decision making. Special Services in the Schools, 2, 5-27.

Deno, S.L., \& Mirkin, P.K. (1977). Data based program modification: A manual. Arlington, VA: Council for Exceptional Children.

Deno, S., Mirkin, P., \& Chiang, B. (1982). Identifying valid measures of reading. Exceptional Children, 49(1), 36-45.

Frumess, S. (1973). A comparison of management groups involving the use of the standard behavior chart. Unpublished doctoral dissertation, University of Texas.

Fuchs, L., Deno, S., \& Mirkin, P. (1984). The effects of frequent curriculum-based measurement and evaluation on pedagogy, student achievement and student awareness of learning. American Educational Research Journal, 21(2), 449-460.

Fuchs, L.S., \& Fuchs, D. (1986 a). Curriculum-based assessment of progress toward long- and short-term goals. Journal of Special Education, 20, 69-82.

Fuchs, L.S., \& Fuchs, D. (1986 b). Effects of systematic formative evalu- ation: A meta-analysis. Exceptional Children, 53, 199-208.

Fuchs, L.S., Fuchs, D., \& Deno, S.L. (1982). Reliability and validity of curriculum-based informal reading inventories. Reading Research Quarterly, 18, 6-26.

Fuchs, L.S., Tindal, G., \& Deno, S.L. (1984). Methodological issues in curriculum-based assessment. Diagnostique, 9, 191-207.

Fuchs, L., Wesson, C., Tindal, G., Mirkin, P., \& Deno, S. (1981). Teacher efficiency in continuous evaluation of IEP goals (Research Report No. 53). Minneapolis: University of Minnesota, Institute for Research on Learning Disabilities.

Fuchs, L., Wesson, C., Tindal, G., Mirkin, P., \& Deno, S. (1982). Instructional changes, student performance, and teacher preferences: The effects of specific measurement and evaluation procedures (Research Report No. 64). Minneapolis: University of Minnesota, Institute for Research on Learning Disabilities.

Galagan, J. (1985). Psychoeducational testing: Turn out the lights, the party's over, Exceptional Children, 52(3), 288-298.

Germann, G., \& Tindal, G. (1985). An application of curriculum-based assessment: The use of direct and repeated measurement. Exceptional Children, 52(3), 288-298.

Howell, K. (1986). Direct assessment of academic performance. In L.S. Fuchs \& D. Fuchs (Eds.), Linking assessment to instructional intervention. School Psychology Review, 15, 324-335.

Jenkins, J., \& Pany, D. (1978). Standardized achievement tests: How useful for special education? Exceptional Children, 44, 448-453.

Liberty, K.A. (1972). Data decision rules (Working Paper No. 20). Eugene: University of Oregon, Regional Resources Center. 
Liberty, K.A. (1975). Decide for progress: Dymanic aims and data decisions. Seattle: University of Washington, Experimental Education Unit, Child Development and Mental Retardation Center.

Marston, D. (in press). Measuring academic progress of students with learning difficulties: A comparison of the semi-logarithmic chart and equal interval graph paper. Exceptional Children.

Marston, D., Deno, S., \& Mirkin, P. (1984). Curriculum-based measurement: An alternative to traditional screening, referral and identification. Journal of Special Education, 18(2), 109-117.

Marston, D., \& Magnusson, D. (1985). Implementing curriculum-based measurement in special and regular education settings. Exceptional Children, 52(3), 266-276.

Mirkin, P., Deno, S., Fuchs, L., Wesson, C., Tindal, G., Marston, D., \& Kuehnle, K. (1981). Procedures to develop and monitor procedures toward progress on IEP goals. Minneapolis: University of Minnesota, Institute for Research on Learning Disabilities.

Mirkin, P., Fuchs, L., \& Deno, S. (1982). Considerations for designing a continuous evaluation system: An integrative review (Monograph No. 20). Minneapolis: University of Minnesota, Institute for Research on Learning Disabilities.

Mirkin, P., Fuchs, L., Tindal, G., Christenson, S., \& Deno, S. (1981). The effect of IEP monitoring strategies on teacher behavior (Research Report No. 62). Minneapolis: University of Minnesota, Institute for Research on Learning Disabilities.

Pennypacker, H.S., Koenig, C.H., \& Lindsley, O.R. (1972). Handbook of the standard behavior chart (prelim.). Kansas City, KS: Precision Media.

Peterson, J., Heistad, D., Peterson, D., \& Reynolds, M. (1985). Montevideo individualized prescriptive instructional management systems. Exceptional Children, 52(3), 239-243.

Shinn, M., \& Marston, D. (1985). Differentiating mildly handicapped, low achieving and regular education students: A curriculum-based approach. Remedial \& Special Education, 6(2), 31-38.

Tindal, G., Fuchs, L., Christenson, S., Mirkin, P., \& Deno, S. (1981). The relationship between student achievement and teacher assessment of short- or long-term goals. (Research Report No. 61). Minneapolis: University of Minnesota, Institute for Research on Learning Disabilities.

Tindal, G., Wesson, C., Mirkin, P., Deno, S., \& Fuchs, L. (1982). Comparison of goal-oriented and program-oriented data utilization procedures (Research Report in preparation). Minneapolis: University of Minnesota, Institute for Research on Leaming Disabilities.

Tucker, J. (1985). Curriculum-based assessment: An introduction. Exceptional Children, 52(3), 199-204.

Wesson, C., King, R.P., \& Deno, S. (1984). Direct and frequent measurement of student performance: If it's good for us, why don't we do it? Learning Disability Quarterly, 7(1), 45-48.

White, O.R. (1977). Behaviorism in special education: An area for debate. In R.D. Kneedler \& S.G. Tarver (Eds.), Changing perspectives in special education. Columbus, $\mathrm{OH}$ : Charles E. Merrill.

White, O.R., \& Haring, N.G. (1980). Exceptional teaching (2nd ed.). Columbus, OH: Charles E. Merrill.

Wolfensberger, W. (1972). The principle of normalization in human services. Toronto: National Institute on Mental Retardation.

\section{Professional update}

\section{NEW BOOKS}

\section{The Special Education Handbook: \\ A Comprehensive Guide for Parents and Educators by Kenneth Shore}

This guidebook may be a worthwhile tool for parents and other professionals to gain an understanding of current special education mandates and IEP development. Introductory material gives an overview of special education. This is followed by a discussion on evaluation. Coverage of the IEP process points out the important role of parents as team members.

The book is highly practical, readable, and specific enough for readers to gain helpful pointers on how to tell if their child may have a problem and how to interact with educators and other professionals, It contains listings of organizations and resources. In paperback, it is available from the Teachers College Press, Columbia University, New York.

\section{They Grow in Silence}

\section{Understanding Deaf Children and Adults} edited by Eugene D. Mindel and McCay Vernon

Anyone who is deaf or is associated with the deaf will appreciate the second edition of this book. Its contributing authors are well versed in their topics, which range from impacts on families, to recent advances in diagnosis, to emotional manifestations of deafness, to speech and language.

Educators may be particularly interested in the discussion of assessment, vocational implications, communication modes and educational practice. Without being lengthy, this book is surprisingly comprehensive. It is in paperback and is published by Little, Brown of Boston. 